\title{
SALT IODIZATION AND IODINE STATUS AMONG INFANTS AND LACTATING MOTHERS IN PAPUA NEW GUINEA
}

\section{Temple VJ ${ }^{1^{*}}$, Oge $\mathbf{R}^{1}$, Daphne $\mathbf{I}^{2}$, Vince $\mathrm{JD}^{3}$, Ripa $\mathrm{P}^{4}$, Delange $\mathrm{F}^{5}$ and CJ Eastman ${ }^{6}$}

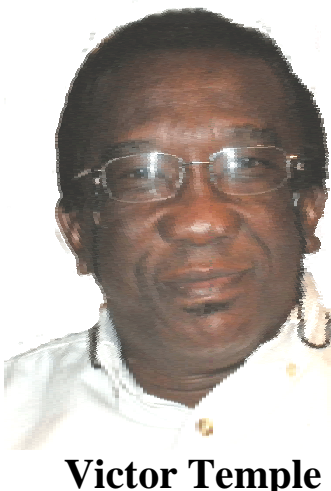

*Corresponding author email: templevictor@gmail.com and/or templevj@upng.ac.pg

${ }^{1}$ Professor of Biochemistry, Division of Basic Medical Sciences, School of Medicine and Health Sciences, University of Papua New Guinea; P. O. Box 5623, Boroko, NCD, Papua New Guinea.

${ }^{1}$ Bachelor of Medical Sciences, and MBBS, Division of Basic Medical Sciences, School of Medicine and Health Sciences, University of Papua New Guinea, P.O. Box 5623, Boroko, NCD, Papua New Guinea.

${ }^{2}$ Bachelor of Pharmacy, Division of Health Sciences, School of Medicine and Health Sciences, University of Papua New Guinea, P.O. Box 5623, Boroko, NCD, Papua New Guinea; Fax: + 675-3232679

${ }^{3}$ FRCP (ED), MD, MRCP, Professor of Child Health Port Moresby General Hospital, Division of Clinical Sciences, School of Medicine and Health Sciences, University of Papua New Guinea, P.O. Box 5623, Boroko, NCD, Papua New Guinea.

${ }^{4}$ MBBS, M. Med, DCH, Division of Clinical Sciences, School of Medicine and Health Sciences, University of Papua New Guinea, University PO Box 320.

${ }^{5} \mathrm{MD}$, PhD, Professor of Paediatrics, c/o Madam Nicole Delange, 153, Avenue de la Fauconnerie, B - 1170, Brussels, Belgium.

${ }^{6} \mathrm{AM}, \mathrm{MD}$, Professor and Director Institute of Clinical Pathology \& Medical Research (ICPMR), Westmead Hospital, Westmead, Sydney, NSW Australia. 


\section{ABSTRACT}

Universal salt iodization is the most effective and sustainable intervention strategy for the prevention, control, and elimination of iodine deficiency. This cross-sectional study assessed the per capita consumption and availability of adequately iodised salt in households, and the iodine status of infants 7 - 120 days old and their lactating mothers in the National Capital District, Papua New Guinea. Salt samples were obtained from households selected by simple random sampling. The mean daily per capita consumption of salt was $5.6 \pm 1.5 \mathrm{~g}$. The mean iodine content in salt from households and trade-stores was $33.38 \pm 18.04 \mathrm{ppm}$ and $44.20 \pm 12.10 \mathrm{ppm}$, respectively. Adequately iodised salt was available in $94.48 \%$ of households and in $100 \%$ of trade-stores. The calculated mean daily per capita discretionary intake of iodine was $186.93 \mathrm{ug}$, which is below the $250 \mathrm{ug}$ recommended for lactating mothers. Casual urine samples selected by simple random sampling were used to determine the iodine status of infants and mothers. Urinary iodine concentration (UIC) was estimated by Sandell-Kolthoff reaction. Mean age of infants was $46.9 \pm 28.2$ days (95\% confidence-interval 41.3 - 52.5 days). Median UIC of infants and of their lactating mothers was 253.5ug/L (interquartile-range 165.3 - 363.0ug/L) and 124.5ug/L (interquartile-range 93.0 - 161.0ug/L), respectively, indicating that iodine deficiency is not of public health significance among infants and lactating mothers. Eighty percent of the infants were exclusively breast-fed and $20 \%$ were mixed-fed. The median UIC for the exclusively breast-fed and mixed-fed infants was $251.0 \mathrm{ug} / \mathrm{L}$ (interquartile-range 177.0 - 338.6ug/L), and 290.0ug/L (interquartile-range 147.1 $425.5 \mathrm{ug} / \mathrm{L})$, respectively, indicating optimal status of iodine nutrition. The UIC of exclusively breast-fed infants was significantly $(\mathrm{P}<0.001)$ higher than the UIC of their mothers. Spearman's correlation test showed weak non-significant linear relationship $(\mathrm{r}=0.118, \mathrm{P}=0.297$ ) between UIC of the exclusively breastfed-infants and their mothers. Despite success in the implementation of the universal salt iodization strategy in the National Capital District, mild to moderate status of iodine nutrition was prevalent in $33.8 \%$ of the exclusively breastfeeding-mothers, although their exclusively breastfed-infants were nourished with iodine. There is, therefore, a need to advocate strongly for increased dietary intake of iodine by lactating mothers. The findings strongly indicate the urgent need for an efficient, sustainable, and functional monitoring system to strengthen and improve on the achievements of the universal salt iodization strategy in National Capital District.

Key words: Iodine, Salt, Urinary, Infants, Mothers 


\section{INTRODUCTION}

Iodine deficiency disorders (IDD) are the adverse health effects associated with inadequate intake of iodine [1]. Universal salt iodization (USI) is the most effective and sustainable intervention strategy for prevention, control, and elimination of iodine deficiency [1-6]. Successful implementation of USI requires effective monitoring, which includes assessment of USI coverage and iodine nutrition status of vulnerable groups in the target population [1-4]. USI has proved to be remarkably effective in many countries, with documented evidence of sustained success of IDD control programs $[1,2,4,5]$. However, there are indications that successful programs of USI do not necessarily cover the needs of lactating mothers and children younger than two years of age [2, 5-7]. Thus, infants may remain exposed to iodine deficiency, which can limit the production of thyroid hormones during the period of rapid growth and development $[2,5-8]$.

For infants under six months of age, breast milk is the major source of iodine for thyroid hormone biosynthesis, followed by infant formula fortified with iodine $[2,5$, 8]. Subclinical (mild to moderate) iodine deficiency in lactating mothers may result in impaired cognitive and psychomotor functions of their infants, making it a public health concern $[2,5,8]$. This underscores the need for continuous evaluation of salt iodization programs and their impact on the vulnerable groups such as lactating mothers and infants in target populations $[1,3,5,8]$.

Universal Salt Iodization strategy was implemented in Papua New Guinea (PNG) in June 1995 with the enactment of the salt legislation, banning importation and sale of non-iodised salt $[9,10]$. Recent data indicate partial fulfilment of the implementation of USI strategy in some areas in PNG [11-14]. Recent publications indicate that sizable number of pregnant and lactating women in PNG have mild to severe status of iodine nutrition $[15,16]$. Published information on per capita consumption of salt, and on iodine content of salt in households and retail shops in National Capital District (NCD), PNG, is scanty.

The National Department of Health (NDOH) in PNG, the UNICEF and WHO regularly conduct awareness campaigns for infants to be exclusively breastfed up to the age of six months, followed by gradual introduction of complementary foods [10, 17-19]. There are, however, no published data on the iodine status of infants in PNG.

The aim of this study was to determine the per capita consumption and availability of adequately iodised salt in households, and the iodine status of infants 7-120 days old and their mothers, resident in NCD.

\section{SUBJECT AND METHODS}

This cross-sectional study was conducted in NCD, which is an incorporated area around Port Moresby, the capital of PNG. NCD is divided into three regions: Moresby North West (MNW), Moresby North East (MNE), and Moresby South (MS) [17]. 
Two of the three regions (MNW and MS) were randomly selected as sampling sites for assessment of the discretionary use of iodised salt and the availability of iodised salt in the households.

Simple random sampling was used to select 150 households in the two regions. Each household was visited at least twice. On the first day, signed informed consent was obtained from the head of each household. The total number of individuals that eat the food prepared in the household was recorded. Three tablespoons $(30-35 \mathrm{~g})$ of the salt available in the household were collected and stored in airtight zip-lock plastic bags for analysis. Each household was then given a pre-weighed $500.0 \mathrm{~g}$ package of salt containing known amount of iodine to use for food preparation and consumption as usual. Each household was revisited five days later. The salt remaining in the package was reweighed to the nearest $0.1 \mathrm{~g}$. The total amount of salt consumed was calculated and considered as the discretionary salt used. Forty salt samples were purchased from randomly selected retail shops in NCD. Standard iodometric titration procedure recommended by the International Council for Control of Iodine Deficiency Disorders (ICCIDD) was used to determine iodine content in all the salt samples [1]. Collection of urine samples was completed before commencement of the procedures for assessing the discretionary use of iodised salt.

The study population for urinary iodine (UI) assessment consisted of 226 randomly selected infants 7-120 days old, attending the Well-Baby Clinic in Port Moresby General Hospital (PMGH) for routine check-ups and immunization. Their 226 lactating mothers were also recruited for the study. PMGH was selected as sampling site, because it is the major public, general, specialist and reference hospital in NCD and PNG; it also serves as the teaching hospital for the School of Medicine and Health Sciences (SMHS). The study sample is, therefore, representative of the NCD population. For comparison with the lactating mothers, 115 age-matched nonpregnant women (control-group) were randomly selected from consented family members of the lactating mothers.

Both infants and women were eligible for recruitment to the study if they were resident in NCD, apparently healthy with no systemic illness, had no history of thyroid disease, kidney disease, and did not use medications that affect thyroid status or disinfectants, antiseptics or contrast agents containing iodine. The non-invasive clean catch technique was used to obtain urine from infants, after inducing micturition by gently percussing or "bouncing" a finger or thumb on the suprapubic area [18]. Casual urine sample was collected from each of the consented women. All urine samples were stored frozen at $-20^{\circ} \mathrm{C}$ until required for analysis.

Assay of urinary iodine concentration (UIC) was by the spectrophotometric method of Sandell-Kolthoff reaction, after digesting the urine with Ammonium Persulfate in a water bath at $100^{\circ} \mathrm{C}$ [1]. Levy Jennings Charts were used for internal UIC Bench Quality Control (QC) characterization, using the Westgard Rules [1]. External QC assessment was by the Centres for Disease Control and Prevention (CDC), Ensuring the Quality of Urinary Iodine Procedures (EQUIP) program. 
Data analysis was by SPSS-PC software (version 11). Kolmogorov-Smirnov and Shapiro-Wilk tests were used to assess normality of UIC. Mann-Whitney U test was used for differences between two groups; Kruskal-Wallis and Friedman were used for comparison of all groups. $\mathrm{P}<0.05$ was considered significant.

The data were interpreted using the WHO/UNICEF/ICCIDD criteria $[1,2,5,7]$. Iodine deficiency is not a public health problem in the target population, if at least $90.0 \%$ of households are using salt with iodine content of $15 \mathrm{ppm}$ or more, the median UIC is not below $100.0 \mathrm{ug} / \mathrm{L}$ and the $20^{\text {th }}$ percentile UIC is not below $50.0 \mathrm{ug} / \mathrm{L}[1,2$, 7]. Specific cut-off points for UIC are used for classifying status of iodine nutrition into different degrees of public health significance $[1,2,7]$. In addition, lactating mothers and infants with median UIC below 150ug/L are categorized as having suboptimal status of iodine nutrition [5].

Ethical clearance was obtained from SMHS UPNG, PMGH, and Medical Research Advisory Committee (MRAC No. 06.24) NDOH PNG. International ethical guidelines for epidemiological studies were implemented in this study [20]. Participation was voluntary, oral and signed informed consent was obtained from each participant and from parents of infants.

\section{RESULTS}

The mean per capita consumption of iodised salt was $5.6 \pm 1.5 \mathrm{~g}$ per day (Mean \pm Standard Deviation), the median was 5.4g per day, the Interquartile Range (IQR) was 4.5-6.6g per day, and the 95\% Confidence Interval (CI) was 5.4-5.9g per day. Salt was not available in five $(3.3 \%)$ of the 150 households. The mean iodine content in salt samples from the 145 households was $33.38 \pm 18.04 \mathrm{ppm}$, median was $26.95 \mathrm{ppm}$, IQR was 16.0-54.0ppm, and 95\% CI was 30.38-36.38ppm. Eight (5.52\%) salt samples had iodine content below the $15 \mathrm{ppm}$, cut-off point. The mean and median iodine content in salt samples from the trade-stores was $44.20 \pm 12.10 \mathrm{ppm}$ and $48.32 \mathrm{ppm}$, respectively. The IQR was $33.78-54.50 \mathrm{ppm}$ and $95 \%$ CI was $40.35-$ $48.05 \mathrm{ppm}$.

One hundred lactating mothers (response rate $44.25 \%$ ) gave consent for collection of urine from their infants. Consent was also obtained from 86 (response rate $74.8 \%$ ) women in the control group. The mean age of all the infants was $46.9 \pm 28.2$ days (95\% CI: 41.3-52.5days); the median age was 35.0days (IQR: 30.0-60.0days). Table 1 shows the UIC values for all the infants. The median UIC was $253.5 \mathrm{ug} / \mathrm{L}$ (IQR: 165.3-363.0ug/L); eight percent of infants had UIC below 100.0ug/L, and $22.0 \%$ had UIC below $150.0 \mathrm{ug} / \mathrm{L}$. Mild to moderate status of iodine nutrition was prevalent in eight percent of all infants (Table 2).

The mean age of the lactating mothers and women in the control group was $25.3 \pm$ 5.5years and $24.2 \pm 6.8$ years, respectively. Table 1 shows the UIC values for lactating mothers and women in control group. As seen in Table 2, mild to moderate status of

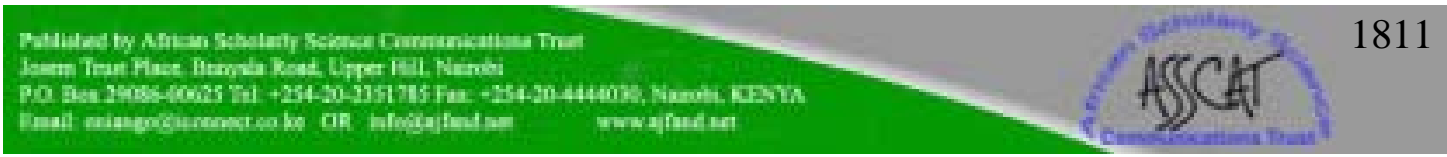


iodine nutrition was prevalent in $31.0 \%$ of lactating mothers and $16.3 \%$ of women in control group.

Comparison of UIC in infants, lactating mothers and women in control group indicates statistically significant $(\mathrm{P}=0.000)$ differences among the three groups. The UIC in lactating mothers was significantly lower $(\mathrm{P}<0.05)$ than in infants and women in the control group. The Spearman's correlation test indicates very weak $(r=0.12$, $\mathrm{P}=0.228$ ) non-significant linear relationship between the UIC in lactating mothers and their infants.

For further analysis of the UI data, the lactating mothers were grouped according to how they fed their infants: exclusive breastfeeding and breastfeeding mixed with baby foods / locally prepared gruels. The UIC data for the lactating mothers and their infants were separated accordingly into sub-groups. For the infants, the sub-groups were Exclusively Breast-Fed Infants (EBF-Infants) and Mixed-Fed Infants (MFInfants). The sub-groups for the lactating mothers were Exclusively Breast-Feeding Mothers (EBF-Mothers) and Mixed-Feeding Mothers (MF-Mothers).

The mean age of the EBF-Infants was $42.6 \pm 26.5$ days (95\% CI: 36.7-48.5days), median age was 30.0days (IQR: 30.0-60.0days). The MF-Infants' mean age was 63.9 \pm 29.3 days (95\% CI: 50.2-77.5days) and their median age was 60.0 days (IQR: 46.590.0days). The EBF-Infants were significantly $(\mathrm{P}=0.004)$ younger than the MFInfants. The UIC values for EBF-Infants and MF-Infants are presented in Table 3. No significant difference $(\mathrm{P}=0.529)$ was observed between the mean UIC of EBF-Infants and that of MF-Infants. Percent of EBF-Infants and that of MF-Infants with UIC below the cut-off points for suboptimal status of iodine nutrition was $8.8 \%$ and $10.0 \%$ respectively. Table 4 shows the percent distribution of UIC according to status of iodine nutrition in the EBF-Infants and MF-Infants.

The mean ages of the EBF-Mothers and MF-Mothers were $25.1 \pm 5.0 y e a r s ~(95 \%$ CI: 21.5-28.8years), and 26.24 \pm 7.16years (95\% CI: 20.9-29.3years), respectively. There was no significant difference $(\mathrm{P}=0.096)$ between the mean ages of the EBF-Mothers and MF-Mothers.

The UIC values of the EBF-Mothers and MF-Mothers are shown in Table 3. The UIC of the EBF-Mothers was significantly lower $(\mathrm{P}=0.012)$ than the UIC of the MFMothers and of women in the control group $(\mathrm{P}=0.000)$. However, no significant difference $(\mathrm{P}=0.3)$ was found between the UIC of the MF-Mothers and women in the control group. Prevalence of mild to moderate status of iodine nutrition was indicated in $33.8 \%$ and $20.0 \%$ of EBF-Mothers and MF-Mothers, respectively (Table 4).

The UIC of the EBF-Infants was significantly $(\mathrm{P}=0.000)$ higher than the UIC of the EBF-Mothers. The Spearman's correlation test showed weak non-significant linear relationship $(\mathrm{r}=0.118, \mathrm{P}=0.297)$ between the UIC of the EBF-Infants and EBFMothers. The UIC of the MF-Infants was significantly $(\mathrm{P}=0.028)$ higher than the UIC 
of the MF-Mothers. A weak non-significant negative correlation $(\mathrm{r}=-0.087, \mathrm{P}=0.71)$ was found between the UIC of the MF-Infants and MF-Mothers.

\section{DISCUSSION}

The mean discretionary salt intake per capita of $5.6 \pm 1.5 \mathrm{~g}$ per day obtained in this study was within the range 3 to $20 \mathrm{~g}$ salt per capita per day consumption reported for other countries $[1,3,5]$. This value was, however lower than the recommended daily per capita salt intake (10.0g) used in formulating the PNG standards for iodine content in salt indicated in the salt legislation $[9,11]$. The $5.6 \mathrm{~g}$ were also lower than the 6.2 to $7.8 \mathrm{~g}$ reported for Lae City and some areas in Central Province in PNG [11, 14]. The value was however, higher than the $2.62 \mathrm{~g}$ reported for Hella region in the Southern Highland Province in PNG [12]. The availability of salt in $96.67 \%$ of households strongly supports the use of salt as the major vehicle for iodine supplementation in NCD.

The mean iodine content $(44.20 \mathrm{ppm})$ in salt samples from the trade-stores was higher than the mean iodine content (33.38ppm) in salt samples in the households. This might be due to the effect of humidity and poor storage of salt in the households. Similar findings have been reported by Jooste et al. [21] and Sankar et al. [22]. In the present study, the iodine content was greater than $15 \mathrm{ppm}$ in 137 of the 145 salt samples, indicating that $94.48 \%$ of the households were consuming adequately iodised salt. All the salt samples from the trade-stores were adequately iodised. These data, according to the WHO/UNICEF/ICCIDD criteria $[1,2,7]$, indicate success in the implementation of the USI strategy in NCD. However, the situation analysis of the status of the USI strategy in NCD can be characterized as "existent but needing strengthening" [1]. WHO/UNICEF recently proposed specific criteria for the categorization of salt iodisation programs in various areas within countries [2]. According to these criteria [2], salt iodization in NCD should be in Group one, because over $90 \%$ of households have access to adequately iodised salt. Therefore, according to WHO/UNICEF guidelines [2], NCD authorities should strive to sustain the achievement of USI and periodically reassess the salt iodization programme and the iodine status of the population.

An effective USI strategy requires systematic monitoring of UIC, which is the key biochemical indicator recommended for assessing the impact of control programs for iodine deficiency [1]. The high non-response rate $(55.75 \%)$ of the infants indicates the difficulty of obtaining biological samples from "apparently" healthy infants, even when the procedure is non-invasive. Similar observations have been reported in the literature [8]. While most of the lactating mothers were willing to provide urine samples, they were very reluctant to have urine samples collected from their infants. The mothers' awareness of the voluntary nature of their consent to having urine collected from their infants is a possible explanation.

The Median $(253.5 \mathrm{ug} / \mathrm{L})$ and $20^{\text {th }}$ percentile (145.6ug/L) UIC obtained for all the infants was greater than $100.0 \mathrm{ug} / \mathrm{L}$ and $50.0 \mathrm{ug} / \mathrm{L}$, respectively, indicating optimal 
status of iodine nutrition. The median UIC for all the infants was lower than values reported for infants in iodine sufficient population in other countries, for example, in Hokkaido, Japan and in Torrance, the United States [5]. The median UIC was, however, higher than values reported for infants in countries with mild to moderate status of iodine nutrition [5]. In the present study, mild to moderate status of iodine nutrition was prevalent in less than $10.0 \%$ of all the infants. However, using the new cut-off point [5], $22.0 \%$ of all the infants had UIC below $150.0 \mathrm{ug} / \mathrm{L}$, which indicates suboptimal status of iodine nutrition. This should be of concern, because up to the age of two years, the brain of the infant is vulnerable to suboptimal intake of iodine, which may cause subclinical iodine deficiency and thus have a devastating effect on child intelligence $[1,5]$.

The median and $20^{\text {th }}$ percentile UIC for lactating mothers $(124.5 \mathrm{ug} / \mathrm{L}$ and $86.0 \mathrm{ug} / \mathrm{L})$ and for women in the control group $(169.5 \mathrm{ug} / \mathrm{L}$ and $103.5 \mathrm{ug} / \mathrm{L})$ indicate that iodine deficiency was not of public health significance in either group of women in NCD [1, $2,7]$. The mean UIC was however, lower than that reported for lactating women in Iran [23]. Our data indicates prevalence of subclinical iodine deficiency among lactating mothers, which becomes more marked with the new cut-off point [5]. It shows that $66.0 \%$ of lactating mothers and $41.9 \%$ of women in control group had UIC below $150.0 \mathrm{ug} / \mathrm{L}$, indicating suboptimal status of iodine nutrition. The higher prevalence of suboptimal status of iodine nutrition among the lactating mothers should be of concern, because of the association between subclinical iodine deficiency in lactating mothers and the potential risk of abnormal brain development in breastfed infants $[1,2,5,6]$. The lower UIC in lactating mothers compared to women in the control group may be due to the loss of iodide in breast milk [1, 5]. In addition, customary taboo in NCD prevents salt intake during pregnancy and lactation, thus salt is usually not added to some locally prepared vegetable meals [19, 24].

Mean per capita intake of $5.6 \mathrm{~g}$ of salt with mean iodine content of $33.38 \mathrm{ppm}$ is equivalent to a calculated mean discretionary intake of $186.93 \mathrm{ug}$ iodine. Assuming that approximately $20.0 \%$ of iodine is lost during food preparation, this is equivalent to a daily per capita intake of $149.54 \mathrm{ug}$ of iodine [1,5]. This amount is lower than the $250.0 \mathrm{ug}$ daily intake of iodine recommended for lactating mothers $[2,5,7]$. It is important that program planners carry out intensive nutrition education, information, and awareness campaigns to advocate for adequate regular intake of iodised salt by lactating mothers. This process must be accompanied by effective monitoring to guard against over consumption of iodine.

Tables 2 and 4 show the percent of infants and mothers at risk of iodine-induced hyperthyroidism (IIH). Most individuals can tolerate relatively high intake of iodine without any obvious adverse effect $[1,3,5]$. However, excessive daily intake of iodine (over 1000.0ug per day) is potentially harmful to susceptible individuals [1, 3, 5].

The median and $20^{\text {th }}$ percentile UIC for the EBF-Infants $(251.0 \mathrm{ug} / \mathrm{L}$ and $148.4 \mathrm{ug} / \mathrm{L})$ and MF-Infants (290.0ug/L and 145.6ug/L) indicate optimal status of iodine nutrition. 
The UIC for the EBF-Infants was lower than that for the MF-Infants, although the difference was not statistically significant. This finding was similar to that reported by Skeaff et al. [8] whose reported median UIC for breast-fed infants was lower than that for formula-fed infants in New Zealand. In this study the data was, however, different from that obtained by Zhang et al. [25] who reported that the UIC of breast-fed infants was higher than that of mixed-fed and bottle-fed infants.

The UIC in $20.0 \%$ of EBF-Infants was below $150 \mathrm{ug} / \mathrm{L}$, compared to $30.0 \%$ in MFInfants. This indicates that the prevalence of suboptimal status of iodine nutrition was lower among the EBF-Infants compared to the MF-Infants. The higher prevalence of suboptimal status of iodine nutrition among the MF-Infants may be due to several reasons. The iodine content in infant milk formulas sold in supermarkets in NCD ranges from 0 to $155 \mathrm{ug}$ per litre. Retail prices of infant milk formulas, fortified with micronutrients, including iodine, are considerably higher than those of the nonfortified brands commonly used by low-income families in PNG [13, 19, 24]. The locally produced complementary foods may contain high amounts of goitrogens, which may further reduce the bioavailability of dietary iodine [13, 19, 24]. In addition, there is a popular belief in NCD that infant food should contain little or no salt; thus, little, if any, salt is usually added to infant gruel prepared locally [13, 19, 24]. Our data strongly support the need for exclusive breast-feeding of infants, especially during the first six months of life, as advocated by WHO/UNICEF $[2,8$, $18,19]$. Salt iodization is effective in increasing the iodine content in human breast milk $[1,5,8]$. Hence, it is important to ensure that the diet of lactating mothers contains adequate amounts of iodine.

According to WHO/UNICEF/ICCIDD criteria [1, 2, 7], the median and $20^{\text {th }}$ percentile UIC for EBF-Mothers (117.5ug/L and 84.0ug/L) and MF-Mothers $(155.0 \mathrm{ug} / \mathrm{L}$ and $117.0 \mathrm{ug} / \mathrm{L}$ ) indicate optimal status of iodine nutrition. However, using the new cut-off point [5], 72.5\% of EBF-Mothers and 40.0\% of MF-Mothers had UIC below 150ug/L. This indicates suboptimal status of iodine nutrition in both groups, with greater severity amongst the EBF-Mothers. Despite the suboptimal status of iodine nutrition of the EBF-Mothers, a relatively higher percentage of iodine replete-infants were observed among the EBF-Infants (80\%), compared with the MF-Infants (70\%). Our data support the findings by Zhang et al. [25], which indicate that, although the EBFMothers were in mild to moderate status of iodine nutrition, the EBF-Infants were nourished with iodine. Evaluation of UIC during lactation may underestimate the iodine intake, because iodine is excreted in breast milk, which is the source of iodine for the EBF-infants [1, 2]. However, adequate dietary intake of iodine is needed during lactation not only to provide for the breast-fed infants but also for maintaining the metabolic status of the mothers $[1,2,5,6]$. Thus, increase in the intake of dietary iodine is recommended during lactation $[2,5,7,16]$. This can be achieved by eating seafoods, such as seaweeds, kelp, nori, fish, and shellfish once or twice a week [1, 16]. In the short term, appropriate multivitamin complex containing iodine and other trace elements can be given to lactating mothers. 


\section{CONCLUSION}

Adequately iodised salt was available in $94.48 \%$ of households and $100.0 \%$ of tradestores in NCD. However, the discretionary daily intake of iodine was below the $250 \mathrm{ug}$ recommended for lactating mothers. Iodine deficiency was not of public health significance among infants and lactating mothers. Despite the success in implementation of USI in NCD, mild to moderate status of iodine nutrition was prevalent in a sizable number of the EBF-mothers, although their infants were nourished with iodine. Our findings strongly indicate the urgent need for nutrition education of mothers, and for an efficient, sustainable, and functional monitoring system to strengthen and improve on the achievements of the USI strategy.

\section{ACKNOWLEDGEMENT}

We acknowledge SMHS Research Grant Committee for funding this project. We thank Olga Temple, Dr. Saweri, Dr. Mokela and Sampson Grant for their support. We are grateful to the lovely babies, their mothers, and Nurses in 'Well-Baby' Clinic PMGH. We thank Dr. K. Caldwell and Dr. A. Makhmudov in CDC/CCEHIP/NCEH USA for providing standard and QC urine samples for our laboratory. 
Table 1:Urinary iodine concentration (UIC) and percent below cut-off points that indicates suboptimal status of iodine nutrition for all infants, lactating mothers, and women in control group

\begin{tabular}{|c|c|c|c|}
\hline & All Infants & Lactating mothers & Control women \\
\hline $\mathrm{n}$ & 100 & 100 & 86 \\
\hline Median UIC (ug/L) & 253.5 & 124.5 & 169.5 \\
\hline \multicolumn{4}{|l|}{ Interquartile Range } \\
\hline UIC (ug/L) & $165.3-363.0$ & $93.0-161.0$ & $106.5-255.5$ \\
\hline Mean UIC (ug/L) & 274.4 & 138.1 & 193.6 \\
\hline Std Deviation & 150.7 & 77.9 & 113.2 \\
\hline 95\% CI: UIC (ug/L) & $244.5-305.3$ & $122.6-153.5$ & $169.3-217.9$ \\
\hline \multicolumn{4}{|l|}{$20^{\text {th }}$ Percentile UIC } \\
\hline (ug/L) & 145.6 & 86.0 & 103.5 \\
\hline \multicolumn{4}{|l|}{ Percent with } \\
\hline $\mathrm{UIC}<50 \mathrm{ug} / \mathrm{L}$ & 1.0 & 3.0 & 8.1 \\
\hline \multicolumn{4}{|l|}{ Percent with } \\
\hline $\mathrm{UIC}<100 \mathrm{ug} / \mathrm{L}$ & 8.0 & 31.0 & 19.8 \\
\hline \multicolumn{4}{|l|}{ Percent with } \\
\hline $\mathrm{UIC}<150 \mathrm{ug} / \mathrm{L}$ & 22.0 & 66.0 & 41.9 \\
\hline
\end{tabular}


Table 2:Distribution of urinary iodine concentration (UIC) of all infants, lactating mothers and women in control group according to range of UIC and status of iodine nutrition

\begin{tabular}{lllll}
\hline Range & Status of Iodine & All Infants & Lactating & Control \\
UIC (ug/L) [1] & Nutrition & $(\mathrm{n}=100)$ & mothers & Women \\
& & & $(\mathrm{n}=100)$ & $(\mathrm{n}=86)$ \\
\hline$<20$ & Sistribution $($ Percent $)$ & 0 & 3.5 \\
$20-49$ & 0 & 3.0 & 4.7 \\
$50-99$ & Moderate & 1.0 & 28.0 & 11.6 \\
$100-199$ & Mild & 7.0 & 57.0 & 33.7 \\
$200-299$ & Optimal & 33.0 & 8.0 & 29.1 \\
$\geq 300$ & Risk of IIH* & 23.0 & 4.0 & 17.4 \\
\hline IIH: Iodine-In & Risk of IIH & 36.0 & & \\
\hline
\end{tabular}

* IIH: Iodine-Induced Hyperthyroidism 
Table 3:Urinary iodine concentration (UIC) and percent below cut-off points that indicates suboptimal status of iodine nutrition for exclusively breastfed-infants (EBF-infants), mixed-fed-infants (MF-infants), exclusively breastfeeding-mothers (EBF-Mothers) and mixed feedingmothers (MF-Mothers)

\begin{tabular}{|c|c|c|c|c|}
\hline \multirow[t]{2}{*}{ Parameters } & \multicolumn{2}{|c|}{ Infants } & \multicolumn{2}{|c|}{ Lactating Mothers } \\
\hline & EBF-Infants & MF-Infants & EBF- & MF- \\
\hline & & & Mothers & Mothers \\
\hline $\mathrm{n}$ & 80 & 20 & 80 & 20 \\
\hline Median UIC (ug/L) & 251.0 & 290.0 & 117.5 & 155.0 \\
\hline Interquartile Range & $177.0-$ & $147.1-$ & $87.1-$ & $122.3-$ \\
\hline UIC (ug/L) & 338.6 & 425.5 & 150.4 & 193.5 \\
\hline Mean UIC (ug/L) & 268.0 & 302.2 & 131.3 & 165.2 \\
\hline Std Deviation & 143.0 & 183.5 & 76.7 & 78.8 \\
\hline \multirow[t]{2}{*}{ 95\% CI: UIC (ug/L) } & $236.1-$ & $216.3-$ & 114.4 & $128.3-$ \\
\hline & 299.8 & 388.1 & 148.4 & 202.0 \\
\hline \multicolumn{5}{|l|}{$20^{\text {th }}$ Percentile UIC } \\
\hline (ug/L) & 148.4 & 145.6 & 84.0 & 117.0 \\
\hline \multicolumn{5}{|l|}{ Percent with } \\
\hline $\mathrm{UIC}<50 \mathrm{ug} / \mathrm{L}$ & 0 & 5.0 & 3.8 & 0 \\
\hline \multicolumn{5}{|l|}{ Percent with } \\
\hline $\mathrm{UIC}<100 \mathrm{ug} / \mathrm{L}$ & 8.8 & 10.0 & 33.7 & 20.0 \\
\hline \multicolumn{5}{|l|}{ Percent with } \\
\hline $\mathrm{UIC}<150 \mathrm{ug} / \mathrm{L}$ & 20.0 & 30.0 & 72.5 & 40.0 \\
\hline
\end{tabular}


Table 4:Distribution (percent) of urinary iodine concentration (UIC) of exclusively breastfed-infants (EBF-infants), mixed-fed-infants (MFinfants), exclusively breastfeeding-mothers (EBF-mothers) and mixed feeding-mothers (MF-mothers) according to range of UIC and status of iodine nutrition

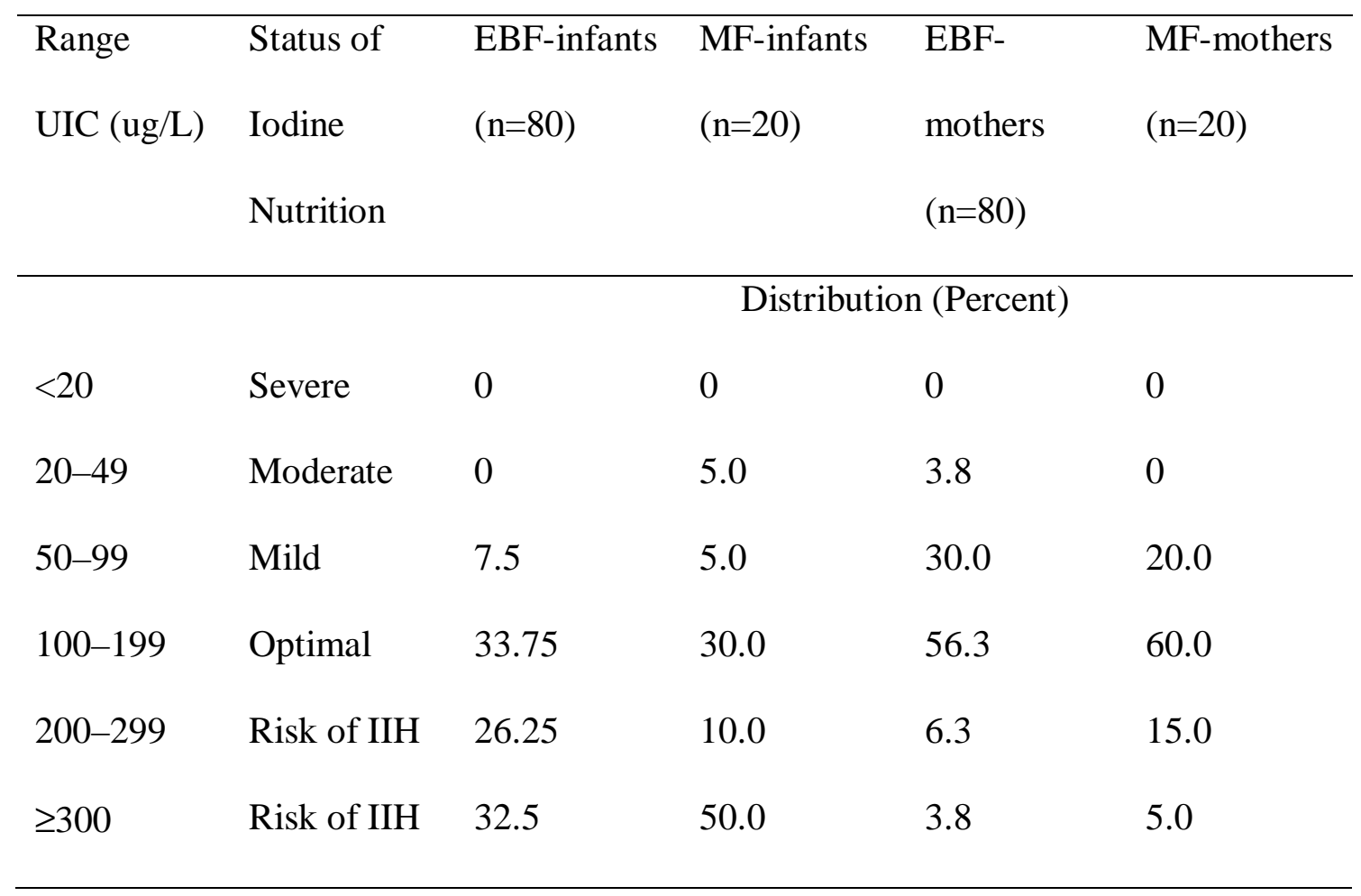




\section{REFERENCES}

1. World Health Organization / United Nations Children's Fund / International Council for Control of Iodine Deficiency Disorders. Assessment of Iodine Deficiency Disorders and monitoring their elimination: A guide for program mangers, $2^{\text {nd }}$ Edition, WHO Publication, Geneva, WHO/NHD/01.1, 2001: 1 - 107.

2. World Health Organization / United Nations Children's Fund Joint statement by WHO and UNICEF: Reaching optimal iodine nutrition in pregnant and lactating women and young children, WHO Publication, Geneva, 2007: 1 2 .

3. Delange F and JT Dunn Iodine deficiency. In: Braverman LE and RT Utiger (Eds). The Thyroid. A Fundamental of Clinical Text. New York and UK: Lippincott, Williams \& Wilkins Publications, Philadelphia, 2005: 264 - 288.

4. Andersson M, Takkouche B, Egli I, Allen HE and B de Benoist Current global iodine status and progress over the last decade towards the elimination of iodine deficiency. Bull. World Health Organ. 2005; 83: 518-525.

5. Delange $\mathbf{F}$ Optimal iodine nutrition during pregnancy, lactation and the neonatal period. Int. J. Endocrinol. Metab. 2004; 2: 1 - 12.

6. Yan YQ, Chen ZP, Yang XM, Liu H, Zhang JX, Zhong W, Yao W, Zhao JK, Zhang ZZ, Hua JL, Li JS, Yu XQ and FR Wang Attention to the hiding iodine deficiency in pregnant and lactating women after universal salt iodization: A multi-community study in China. J. Endocrinol. Invest. 2005; 28 (6): $547-53$.

7. Mangasaryan $\mathbf{N}$ and $\mathbf{B}$ de Benoist Iodine deficiency: An update on global progress and monitoring. In: Report of the first meeting on the Micronutrient Forum $16-18^{\text {th }}$ April 2007, Istanbul, Turkey. Sight and Life Magazine 2007; 3 (Suppl): $39-40$.

8. Skeaff SA, Ferguson EL, Mc Kenzie JE, Valeix P, Gibson RS and CD Thomson Are breast-fed infants and toddlers in New Zealand at risk of iodine deficiency? Nutrition 2005; 21: 325 - 331.

9. Barter P Pure Food Act, amendment of Pure Food Standards. Port Moresby, Papua New Guinea Government, National Gazette 1995; G 47.

10. Children, women, and families in PNG: A situation analysis. Port Moresby: Government of PNG, UNICEF Publications 1996; 20 - 35. 
11. Amoa B, Pikire $\mathbf{T}$ and $\mathbf{P}$ Tine Iodine content in salt in Lae city of Papua New Guinea Asia Pac J. Clin Nutr 1998; 7:128 - 130.

12. Temple VJ, Mapira P, Adeniyi KO and P Sims Iodine deficiency in Papua New Guinea (Sub-clinical iodine deficiency and salt iodization in the highlands of Papua New Guinea). Journal of Public Health 2005; 27: 45 - 48.

13. National Department of Health, United Nations Children's Fund, University of Papua New Guinea, Centers for Disease Control and Prevention National Micronutrient Survey PNG 2005: Draft Summary Report Papua New Guinea National Health Department, Port Moresby. 2006: 1 - 50.

14. Temple VJ Progress towards elimination of iodine deficiency disorders in Papua New Guinea. IDD Newsletter 2006; 22 (4): 11 - 13.

15. Amoa A and L Rubiang Iodine status of pregnant women in Lae. Asia Pac J Clin Nutr 2000; 9 (1): 33 - 35.

16. Temple VJ, Haindapa B, Turare R, Masta A, Amoa AB and P Ripa Status of Iodine Nutrition in Pregnant and Lactating Women in National Capital District, Papua New Guinea. Asia Pac. J. Clin. Nutr. 2006; 15 (4): 533 - 537.

17. National Health Plan 2001 - 2010 Health Vision 2010, National, Provincial and District Health Profiles, Vol. 3, Part 2, Section 1, Port Moresby: Papua New Guinea National Department of Health. August 2000: 38 - 43.

18. Shann $\mathbf{F}$, Biddulph $\mathbf{J}$ and $\mathbf{J}$ Vince Urinary tract infection and urine collection. In: Paediatrics for doctors in Papua New Guinea: A guide for doctors providing health services for children $\left(2^{\text {nd }} E d\right)$. Papua New Guinea Department of Health and Australian-AID Publications, DWU Press. 2003: 378 - 380.

19. Earland J, Harrison $\mathbf{M}$ and $\mathbf{P}$ Robert Nutrition for Papua New Guinea. Papua New Guinea National Department of Health Publications, Port Moresby. 1995: $10-30$.

20. CIOMS. International guidelines for ethical review of epidemiological studies. Council for International Organization of Medical Sciences, Geneva. 1991.

21. Jooste PL, Weight MJ and CJ Lombard Iodine concentration in household salt in South Africa. Bull. World Health Organ. 2001; 79 (6): 534 - 540.

22. Sankar R, Moorthy D, Pandav CS, Tiwari JS and MG Karmarkar Tracking progress towards sustainable elimination of iodine deficiency disorders in Bihar. Indian J. Pediatr. 2006; 73 (9): 799 - 802.

23. Azizi F Iodine nutrition in pregnancy and lactation in Iran. Public Health Nutrition, WHO 2007; 10 (12A): 1596 - 1599. 
24. Gillet $\mathbf{J}$ The health of women in Papua New Guinea. PNG Institute of Medical Research, 1995; Monograph No. 9: Kristen Press, Madang. 1995: 10 - 25.

25. Zhang JH, Xu H, Zhan L, Li X and YT Han Effects of different feeding methods on the iodine status of the infants during the weaning period. Zhonghua Er Ke Za Zhi. 2003; 41(7): 483 - 485. 